\title{
The Impact of Human Resource Development on Organisational Performance: Test of a Causal Model
}

\author{
Anastasia A. Katou \\ University of Macedonia, Greece
}

\begin{abstract}
Although a number of studies have recognized the relationship between human resource development (HRD), and organisational performance, the mechanisms through which HRD leads to organisational performance remain still unexplored. The purpose of this paper is to investigate the pathways leading from HRD to organisational performance by using structural equation modelling. Specifically, we used this analytical tool to test a research framework that is constituted by a set of causal relationships between organisational and other contingencies, resourcing and HRD, skills, attitudes and behaviour, and organisational performance. Employing data from organisations operating in the Greek manufacturing sector, results indicate that the impact of HRD on organisational performance is positive and serially mediated through skills, attitudes and behaviour, and moderated by resourcing, organisational context and other contingencies. Thus, the paper not only supports that HRD has a positive impact on organisational performance but also explains the mechanisms through which HRD improves organisational performance.
\end{abstract}

\section{Introduction}

The issue of theory building within human resource development (HRD) has received less systematic attention in research literature compared to general human resource management (HRM). Specifically, over the past decade a rather small number of authors, such as Swanson \& Holton (1997), Torraco (1997; 2004), Hansen (1998), Chalofsky (1998), Weinberger (1998), Sawson (1998), Hatcher (1999), Lynham (2000), Turnbull (2002), Kuchinke (2003), and Lynham, Chermack, \& Noggle (2004), turned their attention to theory building. However, although HRD theory building is essential for advancing the relatively young HRD profession (Lynham, 2000; Holton, 2002; Hardre, 2003), the issue of variation in HRD strategies has received even less attention in the research literature (Kuchinke, 2003). Business strategies (Horwitz, 1999), firm size and industry (Swanson \& Holton, 2001), staffing strategies that have an impact on training strategies (Raghuram, 1994; Noe, 2002), culture of organization (Baldwing \& Danielson, 2002) may considered to be some variation items in HRD.

Within the resource-based view (RBV) of the firm, which advocates that an organisation can gain competitive advantage by attracting and retaining best human resources, universalistic and contingency HRM-performance linkage models have been either theoretically or empirically developed. The universalistic model suggests that a specified set of HR practices (the so called "best practices") will always produce superior business results whatever the accompanying circumstances. The contingency model argues that an organisation's set of HRM policies and practices will be effective if it is consistent with other organisational strategies. However, there 
is no consensus amongst researchers regarding which model is the predominant one (Wood, 1999).

With respect to the HRD-performance linkage model building literature, although Wimbiscus (1995) supports the view that HRD lacks a unifying model that may be used to understand HRD issues, most current HRD models are following the universalistic rather than the contingency perspective (Kuchinke, 2003). Training (Holton \& Naquin, 2005) and employability (Garavan, McGuire \& O'Donnell, 2004) are assumed to be the basic components for people to acquire competencies that in turn will significantly improve organizational performance. However, there is a small number of authors, most notably Snell, Lepak, \& Youndt (1999), who advocate that investment in human resources may be contingent on the specific characteristics and contribution of groups of employees to the organization. More recently, Mabey \& Gooderham (2005) and Mabey \& Ramirez (2005) in examining the impact of management development on organizational performance in six European firms found that contextual factors like sales turnover, size and country explained some of the variance in perceptions of organizational performance.

In analysing the impact of HRM on organisational performance each of the HRMperformance linkage models developed complements the others by adding constructs, variables or relationships (Alcazar, Fernandez, \& Gardey, 2005). A serious limitation that recent reviews of the literature points out is that the link between HRM and business performance is considered like a 'black box', i.e., lack of clarity regarding 'what exactly leads to what' (Gerhart, 2005; Alcazar et al., 2005). In empirically investigating these models most studies were based on cross-sectional data and the analysis employed was either 'hierarchical regression models' or 'competing regression models' without proving causality. Thus, Becker and Gerhart (1996) and Fey, Bjorkman \& Pavlovskaya (2000) exhorted researchers to use 'structural equation modelling' (SEM) to illuminate the 'black box' (Wright, Gardner, \& Moynihan, 2003) between HRM systems and organisational performance. This is because the use of SEM is particularly appropriate when testing direct and indirect relationships between HRM policies and organisational performance and when testing theoretically derived paths among various exogenous and endogenous variables.

The same picture holds for the HRD-performance linkage models, where the contributions in HRD literature remain in most cases descriptive or prescriptive (Ellinger, Ellinger, Yang, \& Howton, 2002). Despite the fact that training is expanding, it still remains concern over the contribution of training to organizational performance (Bartlett, 2001). Empirical work in this area is lacking and according to Garavan, Gunnigle \& Morley (2000) there are no models yet that properly evaluate the extent to which HRD improves performance. In fact there is little empirical support indicating that HRD positively affects organizational performance (Torraco, 1999; Bartlett, 2001). However, applying SEM, Tracey, Hinkin, Tannenbaum, \& Mathieu (2001) found that training outcomes are related with pre-training context, and are mediated by self-efficacy and motivation. Moreover, Mabey \& Gooderham (2005) and Mabey \& Ramirez (2005) sustain that organizational fit mediates strategic fit and perceptions of the importance given to management development, which subsequently determines improved organizational performance. Similarly, Lopez, Peon, \& Ordas (2005) support the view that organizational learning mediates the 
relationship between HR practices and business performance. Specifically, by using SEM they found that HR practices have a positive impact on organizational learning, which in turn has a positive effect on business performance.

According to the discussion above, the primary research questions of this paper are:

1. What impact, if any, does human resource development have upon organizational performance?

2. What is the causal path of this relationship?

3. What is the contingency framework of this relationship?

A supplementary goal in this paper is to empirically investigate the research questions by employing the structural equation modelling methodology, instead of the usual regression equation methodology. Considering further, that there are no studies that test theoretically derived paths among various exogenous and endogenous variables in the Greek context, an attempt has been made in this paper to investigate how human resource development influences organisational performance in the Greek context.

\section{Research Model and Hypotheses}

Considering Black (2001: 26), who advocates that "three key elements are required for any successful SEM analysis: strong theory, a well-specified measurement model, and a sound modelling strategy", the purpose of this section is to present a strong theory for linking HRD with organizational performance, because there is a substantial lack in HRD theory building (Lynham, 2000). We start with the Becker and Huselid (1998) HRM-performance linkage model, which has been categorised as the "most logical and definite model of the processes through which HR practices affect firm performance" (Wright et al., 2003: 25). The core philosophy of this model suggests that HR practices have a direct impact on employee skills and motivation, which are subsequently translated into improved operating performance, that has a direct impact on financial performance.

Based on this philosophy we suggest in this paper a model that diverging from the HRM-performance linkage models of Becker and Huselid (1998) and Wright et al. (2003), employs the logic of the resource-based view perspective for explaining competitive advantage, focusing on one specific HRM practice, that of human resource development (Mabey \& Gooderham, 2005), whose objective is to increase employees' abilities and motivation, which in turn ultimately improve organizational performance (Lopez et al., 2005). A central element of the RBV of human resources is the positive relationship between HRD and organizational performance (Mayo, 2000; Mabey \& Ramirez, 2005). The RBV perspective advocates that the potential for competitive advantage of an organisation is based on its ability to exploit the inimitable characteristics of its pool of resources and capabilities, supporting thus, that differences in business performance can be ascribed to the inimitable features of its resources and capabilities. It is further argued that technological progress is no longer a source of competitive advantage, and instead, it has been realised that human resource management has a positive impact on organisational performance (Ferris, Perrewe, Ranft, Zinko, Stoner, Brouer, \& Laird, 2007). Although, the impact of the RBV philosophy on human resource management research was very 
important, the bottom line for HRD is to improve organizational performance (Swanson, 1995). The usual line of work in this case is to investigate the relationship between HRD and commitment, which in turn is positively related to organizational performance (Bates, 1999). However, the investigation of HRD and organizational commitment as an outcome of training and development is still in early stages (Bartlett, 2001).

The pool of employee resources and capabilities of an organisation, on which the RBV perspective is based, considerably depends on employee resourcing and development (Appelbaum \& Reichart, 1998). Raghuram (1994) argues that staffing and training lie at the hart of the processes aiming at developing the necessary skills for maintaining competitive advantage and organizational performance. Although it is true that the source of competitive advantage refers to the human resources themselves and not to the policies employed to attract, utilise and retain them, recruiting and selection may be considered to be a good starting point for building a pool of superior employee resources and capabilities. Individual and team training and development may be employed to add new skills to the existing employee resources and capabilities. Increasing employee skills and abilities are expected to create future returns through increased productivity and business performance (Shih, Chiang, \& Hsu, 2006). The processes of resourcing and development aiming at providing increased skills to employees have a direct impact on the attitudes of employees, such as motivation, commitment and satisfaction (Bartlett, 2001; Fey et al., 2000; Wright et al., 2003). Specifically, a large body of research considers motivation to be a key determinant of performance (Hardre, 2003). Employees' attitudes and behaviours generally depend on the policies and procedures the organisation is employing. Specifically, "training and development may convey a message to employees that it is in the best interest of the organisation to have employees stay longer in the firm" (Katou \& Budhwar, 2007: 28). This message to employees may be translated into employee behaviours, such as staying long within the organisation (counterpart of turnover) and be present (counterpart of absenteeism) (Guest, 2001). In fact, according to the job performance theory (Campbell, 1990), it is employee's attitudes that have an impact on the behaviour of employees that subsequently has an impact on organisational performance (Wright et al., 2003). In particular, it has been argued that turnover is heavily influenced by job satisfaction, motivation (Hardre, 2003) and organisational commitment. No employee would like to stay with an organisation if he is not satisfied with his work and if he looses his motivation and commitment to the organisation (Elangovan, 2001; Chiu \& Francesco, 2003). However, although it is argued that satisfaction usually precedes organisational motivation and commitment, it is suggested that job satisfaction and organisational motivation and commitment are strongly interrelated (Bartlett, 2001). Other authors support the hypothesis that it is commitment that causes satisfaction (Vandenberg \& Lance, 1992). Thus, it is suggested that more research should be undertaken to examine the relationship between training and commitment (Bartlett, 2001).

The discussion above suggests the following basic causal pathway:

Resourcing $\rightarrow$ Development $\rightarrow$ Skills $\rightarrow$ Attitudes $\rightarrow$ Behaviour $\rightarrow$ Performance 
Considering this causal pathway, the general framework of mediating models refers to an 'indirect linkage' and/or 'hierarchical linkage' (Black, 2001) through the outcomes of skills, attitudes, and behaviour between development and organizational performance. In these models we may also see a "direct linkage", between the individual policies of resourcing and development and the individual outcomes of skils, attitudes, and behaviour, and organizational performance (Schuler \& Jackson, 1999). However, it is not required these linkages to be simultaneously present. It is very possible even in the absence of a direct linkage, some policies to significantly contribute to organizational performance through the intervening process.

Furthermore, this intervening process may be 'moderated' by organisational contextual variables (Miles \& Snow, 1984; Trompenaars, 1993; Budhwar \& Sparrow, 1997; Lopez et al., 2005) and other contingencies (Delaney \& Huselid, 1996). By appropriately managing human resources development and considering moderating organisational features, such as management style, and organisational culture, or other contingency features, such as size, life cycle stage, union intensity, and capital intensity, HRD has the potential to be a source of competitive advantage (Ferris et al., 2007).

The major objective of mediating-moderating models has been to determine the extent to which individual HRM policies and/or HRM systems directly or indirectly enhance business performance (Katou \& Budhwar, 2006). This objective can be transferred to the HRD-performance linkage model that is presented in Figure 1, which is constituted by two parts: The mediating part, that has been presented above as the basic causal pathway, refers mainly to the variables (circles) of the policies of resourcing and development, the outcomes of skills, attitudes, and behaviour, and organisational performance. The moderating part refers mainly to the variables of organisational context, and other contingencies. The contingency variables to resourcing and development may include such items as size, industry, capital intensity, and labour intensity, whilst organizational context variables that may have a more strategic role to the organization include items such as management style and organizational culture (Mabey \& Ramirez, 2005). The arrows connecting two circles (variables) indicate the hypotheses to be tested, as follows:

H1: Organisational context factors moderate organisational performance (H1-2), and employees' resourcing (H1-1), development (H1-6), skills (H1-3), attitudes (H1-4) and behaviour (H1-5).

$\mathrm{H} 2$ : Contingency factors moderate organisational performance $(\mathrm{H} 2-2)$, and employees' resourcing (H2-1), development (H2-6), skills (H2-3), attitudes (H24) and behaviour (H2-5).

H3: Employees' resourcing is positively related with organisational performance (H3-1), and employees' development (H3-2), skills (H3-3), attitudes (H3-4) and behaviour (H3-5).

H4: Employees' development is positively related with organisational performance (H4-1), and employees' skills (H4-2), attitudes (H4-3) and behaviour (H4-4). 


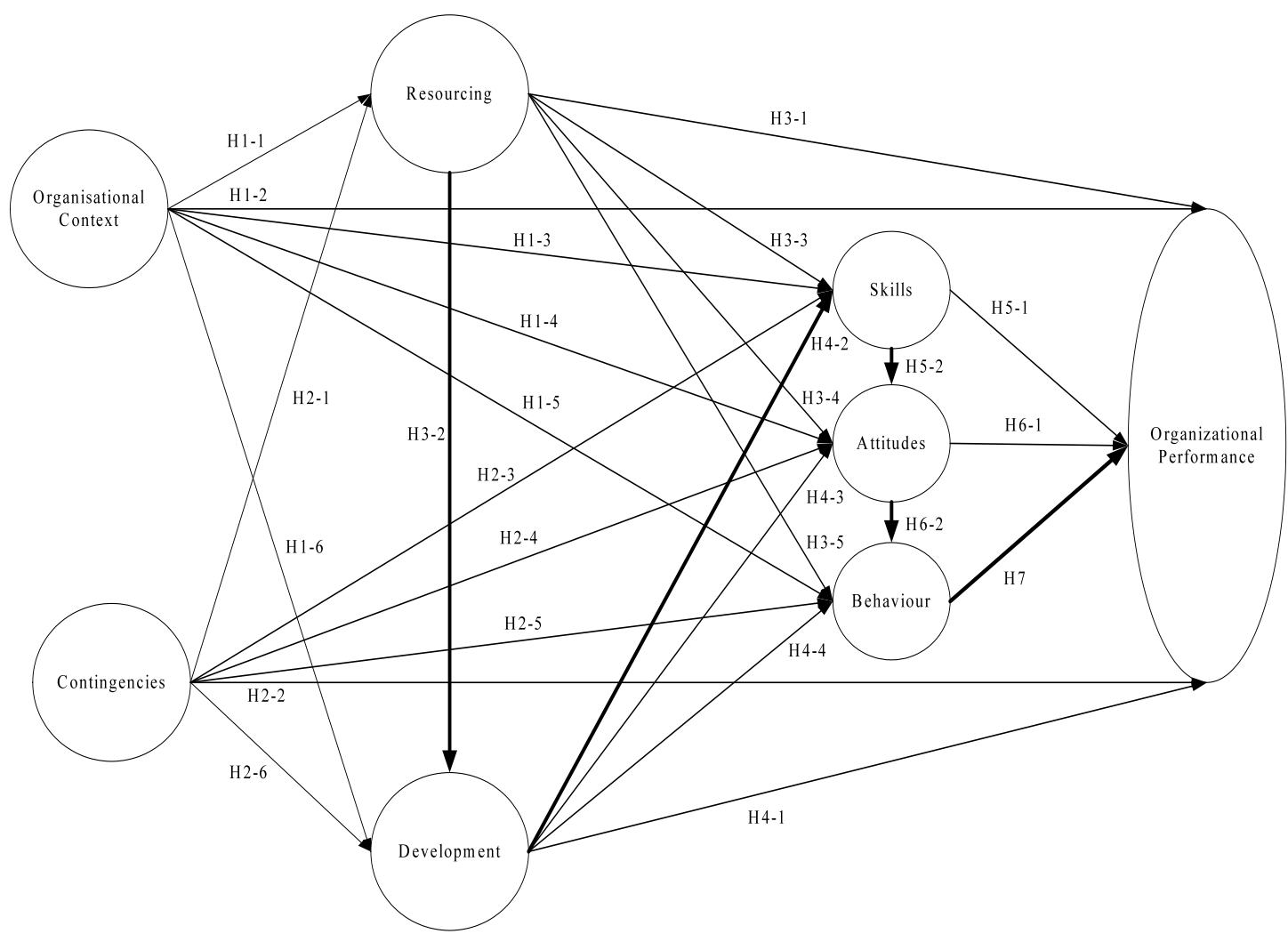

Figure 1: An HRD-performance linkage hypothesised causal model

H5: Employees' skills are positively related with employees' attitudes (H5-2), and organisational performance (H5-1).

H6: Employees' attitudes are positively related with employees' behaviour (H6-2), and organisational performance (H6-1).

H7: Employees' behaviour is positively related with organisational performance.

According to the basic characteristics of the model proposed in Figure 1, organisational and contingency factors moderate the policies of resourcing and development, the outcomes of skills, attitudes, and behaviour, and organisational performance. Furthermore, resourcing precedes development, which precedes skills, that precedes attitudes, that precedes behaviour, which precedes organisational performance. An analogy may be made between the concepts presented in Figure 1 and Kirkpatrick's (1998) four-level model: level-one evaluation is equivalent to the assessment of resourcing as an input of HRD, level two refers to the actual process of HRD, level three evaluates the output of HRD (skills, attitudes, behaviour), and level four measures organizational performance as an impact derived by HRD (Wang, Dou, \& Li, 2002).

Specifically, although it is expected organisational context and contingencies to be associated with organisational performance, skills, attitudes, and behaviour, and resourcing and HRD, the sign of this association depends on the specific variables constituting the organisational context and contingencies constructs (Wang, 2000). 
For example, capital intensity and employment size that are two of the major variables constituting contingencies, it is expected to positively be associated with organisational performance (Richard \& Johnson, 2001). On the contrary, life cycle stage and union intensity may not be positively associated with organisational performance (Delbridge \& Whitfield, 2001). Similarly, organisational context is expected to positively (Budhwar \& Sparrow, 1997) or negatively (Miles and Snow, 1984; Trompenaars, 1993) be associated with HRM policies and outcomes, depending on the specific constructs used. Furthermore, many studies have shown that behaviour may not affect productivity (Pritchard, 1992).

The picture with respect to the interrelationships of primary interest that are depicted in Figure 1 by the bold arrows of hypotheses H3-2, H4-2, H5-2, H6-2 and H7, is clear. For example, Doty \& Delery (1997) argued that HRM policies positively influence firm performance by creating a workforce that is skilled, motivated, and empowered. Fey et al. (2000) provided some support for the use of employee skills, attitudes, motivation, retention and development as mediating variables between HRM policies and firm performance. Guest (2001) used employee satisfaction and commitment, or employee quality, commitment and flexibility, as mediating variables. Boselie, Paauwe, \& Jansen, (2001) indicated employee satisfaction, motivation, retention, presence, social climate, and involvement as mediating outcomes between HRM policies and firm performance. Paul \& Anantharaman (2003) indicated that the intervening variables of employee competence, teamwork, organisational commitment, and customer orientation affect the organisational performance variables of employee retention, employee productivity, product quality, speed of delivery, operating cost, which then determine financial performance.

\section{Methodology}

\section{Sample}

A large questionnaire survey in 23 sector industries in the Greek manufacturing sector was carried out between March 2002 and September 2002. A sample of 600 organisations was used from the main Greek directory - ICAP Group, which is the only Greek company recognized by the Bank of Greece as an External Credit Assessment Institution and includes incorporated and limited liability companies. The sample was obtained by employing the stratified methodology. The strata were the 23 manufacturing sector industries including organisations with more than 20 employees. 20 percent of the approximately 3000 organisations were randomly chosen from each stratum of the directory. One hundred and seventy eight (178) usable questionnaires in terms of completeness were received, a response rate of approximately 30 percent.

Most of the questions for the survey were drawn from existing international HRM surveys, such as the Price Waterhouse Cranfield Project Survey (Brewster \& Hegewisch, 1994) and Hall and Torrington (1998). The questionnaire was originally developed in English, then, it was translated into Greek, and finally translated back from Greek to English. The survey questionnaire it was completed by one person responsible in each firm for the HRM function. We acknowledge this as a limitation. However, the application of Harman's single factor test (Harman, 1967) to all the relevant variables in the model, using the eigenvalue greater than one criterion, 
revealed seven factors, and not just one, with the first factor explaining 26.9 percent of the variance in the data which is not relatively very high. According to this test if a significant amount of common method bias exists in the data, then the factor analysis of all the relevant variables in the model will generate a single factor that accounts for most of the variance. Thus, we believe that the common method bias in the data was relatively limited.

\section{Measures}

\section{$\underline{\text { Resourcing-related variables }}$}

Resourcing is one of the basic factors that explains HRD (Kuchinke, 2003). However, although recruitment and selection activities search for desired skills of employees, emphasis should also be given on characteristics of individuals that may create cooperation and cultural fit (Williams, 2001). For the development of the resourcing construct we used four items referring to recruitment, selection, separation, and flexible work arrangements (Katou \& Budhwar, 2007). These items were measured on a scale ranging from $1=$ not at all effective to $5=$ highly effective. For example, the exact wording for the recruitment item is, "In your opinion, how effective is your recruitment process?" and for the selection item is, "In your opinion, how effective is your selection process?"

\section{$\underline{\text { Training-related variables }}$}

For the development of the training construct we used five items referring to individual and team training and development, monitoring training and development, career development, work design, and performance appraisal (Katou \& Budhwar, 2007). These items were measured on a scale ranging from $1=$ not at all effective to $5=$ highly effective. For example, the exact wording for the training and development item is, "In your opinion, how effective are your employee training and development programmes?" and for the work design item is, "In your opinion, how effective are your work design programmes?"

\section{$\underline{\text { Skills }}$}

For the development of the skills construct we used three items referring to competency, cooperation between management and employees, and cooperation among employees. This is because although competencies are assumed to be foundational to all performance improvement (Horwitz, 1999; Hardre, 2003), they are not sufficient for improving organizational performance unless employees are cooperated and motivated (Lopez et al., 2005). These items were measured on a scale ranging from $1=$ very bad to $5=$ very good, asking respondents to report HRM performance (skills) over the past 3 years in order to minimize random fluctuations and anomalies in the data. For example, the exact wording for the competency item is, "How would you rate employee competences over the past 3 years?" and for the cooperation among employees item is, "How would you rate cooperation among employees in general over the past 3 years?" 


\section{Attitudes}

Motivation, organizational commitment, and satisfaction constituted the attitudes construct (Guest, 2001). These items were measured on a scale ranging from $1=$ very bad to $5=$ very good, asking respondents to report HRM performance (attitudes) over the past 3 years in order to minimize random fluctuations and anomalies in the data. For example, the exact wording for the motivation item is, "How would you rate employee motivation over the past 3 years?" and for the satisfaction item is, "How would you rate employee satisfaction over the past 3 years?"

\section{Behaviour}

Employees staying within the organisation (retention, counterpart of turnover), and presence (counterpart of absenteeism) constituted the behaviour construct (Guest, 2001). These items were measured on a scale ranging from $1=$ very bad to $5=$ very good, asking respondents to report HRM performance (behaviour) over the past 3 years in order to minimize random fluctuations and anomalies in the data. For example, the exact wording for the retention item is, "How would you rate employee retention over the past 3 years?" and for the presence item is, "How would you rate employee presence over the past 3 years?"

\section{Organisational Performance}

The dependent variable of organizational performance measures the bottom-line results on which HRD has an impact (Wang et al., 2002). The organisational performance construct is usually indicated by items such as effectiveness, i.e. if the organisation meets its objectives, efficiency, i.e. if the organisation uses the fewest possible resources to meet its objectives, development, i.e. if the organisation is developing in its capacity to meet future opportunities and challenges, satisfaction, of all participants - owners and investors, customers, society, other organizations, and organization members, innovation, for products and processes, and quality, $\%$ of products of high quality. These items were measured on a scale ranging from $1=$ very bad to $5=$ very good, asking respondents to report organisational performance over the past 3 years in order to minimize random fluctuations and anomalies in the data. For example, the exact wording for the effectiveness item is, "How would you rate the overall organisation's effectiveness over the past 3 years?" and for the efficiency item is, "How would you rate the overall organisation's efficiency over the past 3 years?"

\section{Organisational contextual variables}

An organization's intangible features may strongly influence its competitive position in the market (Kuchinke, 2003). Such features may be 'management style' ( $1=$ heavily centralised to $5=$ heavily decentralised) (Miles \& Snow, 1984; Lopez et al., 2005), and 'organisational culture' ( 1 = power-oriented, 2 = role-oriented, 3 = projectoriented, 4 = fulfilment-oriented) (Trompenaars, 1993; Lopez et al., 2005). 


\section{Contingencies}

Several contingencies may influence the adoption of resourcing and development, skills, attitudes, and behaviour, and performance (Kuchinke, 2003; Mabey \& Gooderham, 2005), such as 'size' (employment in logs) that may influence the amount of resourcing and training 'life cycle stage' (introductory, growth, maturity, decline, turnaround) that may influence resourcing and development, 'union intensity' (percent of employees in unions) that may influence HRD policies and performances, 'capital intensity' (total assets by employment, in logs).

\section{Consistency of the survey instrument}

Construct internal consistency was checked computing Cronbach alphas (Nunnally, 1978). Alpha values of 0.70 or higher were acceptable, with 0.60 being moderately acceptable. Cronbach alphas reported in Table 1, ranged from 0.601 to 0.929 , indicating thus that the survey instrument is a reliable instrument for checking the causal model presented in Figure 1. Content validity was examined to ensure an adequate and representative set of items that would tap the concept (Sekaran, 1992). We evaluated the percent of the total variance explained per dimension (latent variable) obtained by applying confirmatory factor analysis using varimax rotation and eigenvalues greater than one. The percent of total variance explained values reported in Table 1, are much higher than $50.0 \%$ (except for the 'contingencies') indicating thus an acceptable survey instrument (Hair, Anderson, Tatham \& Black, 1995).

\section{$\underline{\text { Statistical analysis }}$}

To test the raised research questions of the proposed framework the methodology of 'structural equation models' or 'latent variable models' was used, which is much more powerful than regression analysis in investigating causal relationships between categorical variables (Hair et al., 1995).

\section{Results}

We tested the theoretical model presented in Figure 1 using the structural equation modelling via the Statistical Package LISREL (Linear Structural Relations) and the maximum likelihood estimation (MLE) (see Jöreskog \& Sörbom, 2004). We used MLE because tests of departure from normality, skewness and kurtosis for all variables used were all (except for 'union intensity') within acceptable statistical limits. Furthermore, the sample size of 178 in this study is within the range of 100 to 200 for using MLE procedures (Hair et al., 1995). Finally, the constructs reliability and the variance extracted for all the constructs of the estimated model were verified, because the corresponding results reported in Table 1 were high and above the acceptance levels of 0.70 for construct reliability and of 0.50 for variance extracted (except for 'contingencies') (Hair et al., 1995).

We assessed the overall model fit employing the chi-square test and the normed-chisquare test and examining the root mean squared error of approximation (RMSEA), the comparative fit index (CFI), and the normed fit index (NFI). A non-significant chisquare (i.e. $p>0.05$ ) indicates that the proposed model is an adequate presentation 
of the entire set of relationships. However, in cases of significant chi-squares and high numbers of degrees of freedom, the value of the normed-chi-square (i.e. value of chi-square / degrees of freedom) should be used. A value of the normed chisquare between 1 and 3 indicates that the proposed model is an adequate presentation of the entire set of relationships. The RMSEA considers the fit of the model to the population covariance / correlation matrix. A value of RMSEA less than 0.08 or 0.10 represents a good or a reasonable approximation respectively (Lopez et al., 2005). The CFI and the NFI trace the relative improvement of the assessed model over a null where all observed variables are assumed to be uncorrelated. The $\mathrm{CFI}$ and NFI range from zero to 1.00 , with values over 0.90 indicating a well-fitting model (Hair et al., 1995).

Table 1: Factor analysis and SEM statistics

\begin{tabular}{lcccc}
\hline Constructs & \multicolumn{2}{c}{$\begin{array}{c}\text { Factor Analysis } \\
\text { Statistics }\end{array}$} & \multicolumn{2}{c}{ SEM Statistics } \\
\cline { 2 - 5 } & $\begin{array}{c}\text { Percent of } \\
\text { Variance } \\
\text { explained }\end{array}$ & $\begin{array}{c}\text { Cronbach } \\
\text { Alphas }\end{array}$ & $\begin{array}{c}\text { Constructs } \\
\text { reliability }\end{array}$ & $\begin{array}{c}\text { Variance } \\
\text { extracted }\end{array}$ \\
\hline Resourcing & 63.238 & 0.800 & 0.8069 & 0.5271 \\
Development & 68.437 & 0.884 & 0.8596 & 0.5529 \\
Organisational performance & 74.474 & 0.929 & 0.9229 & 0.6690 \\
Skills & 85.255 & 0.913 & 0.9135 & 0.7794 \\
Attitudes & 85.043 & 0.910 & 0.8361 & 0.6311 \\
Behaviour & 86.878 & 0.849 & 0.8607 & 0.7557 \\
Contingencies & 48.838 & 0.629 & 0.7152 & 0.4038 \\
Organisational context & 71.668 & 0.601 & 0.7874 & 0.6495 \\
\hline
\end{tabular}

Each latent variable model is accompanied with a path diagram indicating all the causal relationships between the variables involved. The path diagram for the estimated HRD-performance linkage model proposed in Figure 1 is presented in Figure 2. In this figure the boxes represent exogenous or endogenous observed variables and the circles represent the related latent variables. The light arrows indicate the observed variables that constitute the related latent variable and the bold arrows indicate the structural relationships between the corresponding variables. The figures that are assigned to each arrow show the estimated standardised coefficients. The statistics presented in Figure 2 suggest that our estimated model possesses a satisfactory degree of fit with the data (Normed Chi-Square $=2.698$, RMSEA $=0.098, \mathrm{CFI}=0.96, \mathrm{NFI}=0.94)$. Furthermore, all the estimated standardised coefficients are statistically significant and their values in most cases are high enough.

Turning now to the SEM specific results the significant arrows between the various variables of the model suggest the following relationships:

- Organisational context (management style, organisational culture) directly influences resourcing (0.81), development $(0.16)$, skills $(0.45)$, and attitudes (0.68), supporting thus hypotheses $\mathrm{H} 1-1, \mathrm{H} 1-6, \mathrm{H} 1-3$ and $\mathrm{H} 1-4$ respectively. 
- Contingencies (life cycle stage, union intensity, capital intensity, size) directly influences $(-0.10)$ organisational performance, supporting thus hypothesis $\mathrm{H} 2-2$.

- Resourcing (recruitment, selection, separation, flexible work) directly influences development (0.74), supporting thus hypothesis H3-2.

- Development (training and development, monitoring training and development, careers, work design, performance appraisal) directly influences skills (0.44) and organisational performance (0.33), supporting thus hypotheses $\mathrm{H} 4-2$ and $\mathrm{H} 4-1$ respectively.

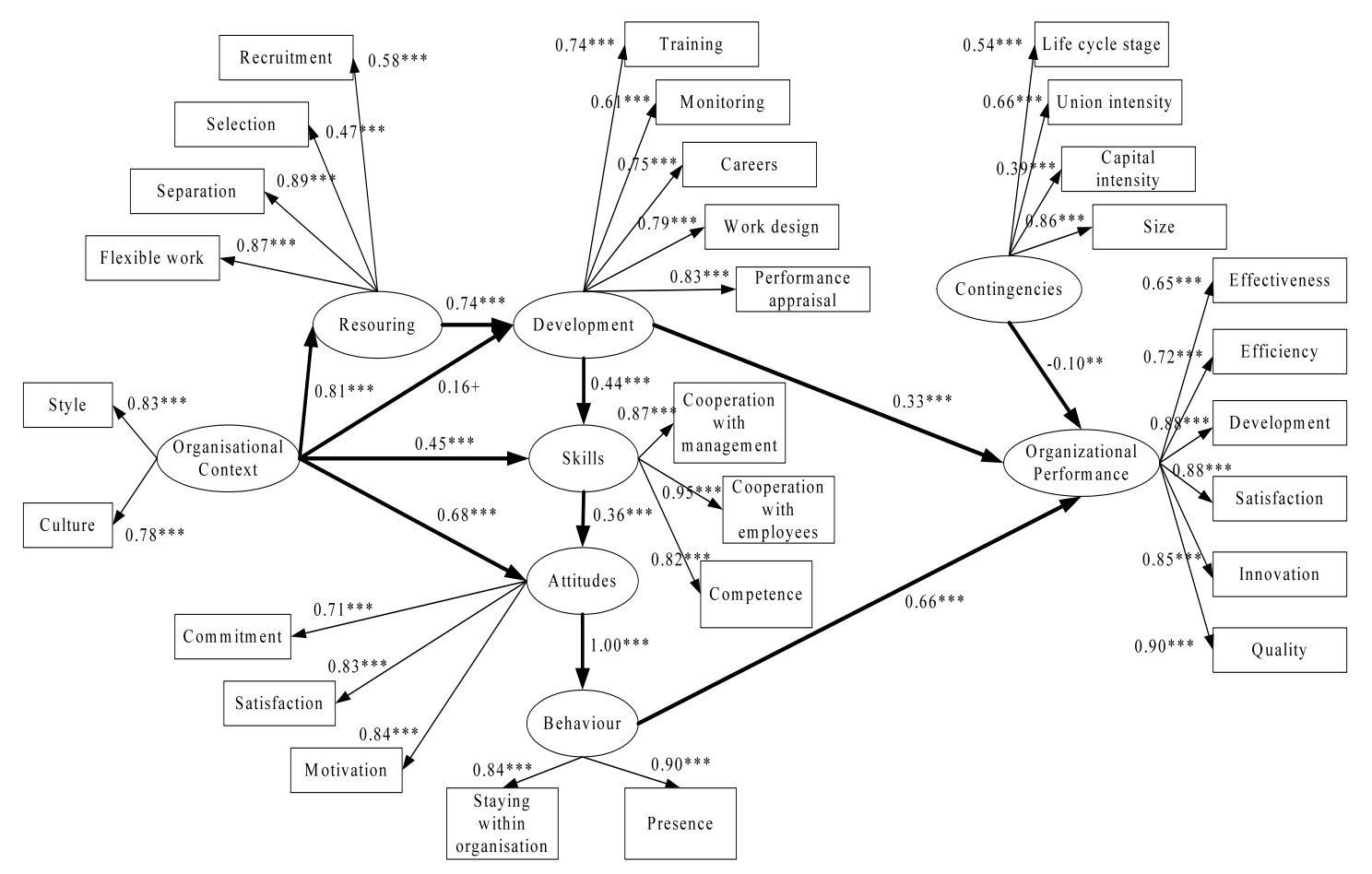

Chi-Square $=984.90 \mathrm{df}=365 \mathrm{p}$-value $=0.000$ Normed Chi-Square $=2.698$ RMSEA $=0.098 \mathrm{CFI}=0.96 \mathrm{NFI}=0.94$ $+\mathrm{p}<0.10,{ }^{*} \mathrm{p}<0.05,{ }^{* *} \mathrm{p}<0.01{ }^{* * *} \mathrm{p}<0.001$

Figure 2: The Estimated Model using LISREL

- Skills (cooperation with management, cooperation with employees, competence) directly influences attitudes (0.36), supporting thus hypothesis H5-2.

- Attitudes (commitment, satisfaction, motivation) directly influences behaviour (1.00), supporting thus hypothesis H6-2.

- Behaviour (retention, presence) directly influences organisational performance (0.66), supporting thus hypothesis $\mathrm{H} 7$.

\section{Discussion and Conclusions}

Previous studies investigating HRD-performance linkage models were usually based either on hierarchical regression analysis for testing whether contingencies moderate HRD policies or on competing regression analysis for testing whether HRD outcomes mediate HRD policies and organisational performance. In the present study we have adopted the different analytical tool of the structural equation modelling, which is much more powerful in investigating causal relationships between categorical variables. Furthermore, employing the resource-based view perspective, the proposed and tested conceptual HRD-performance linkage 
framework put some light into the 'black box' mediating employee resourcing and development, and organisational performance, by also considering the moderating effects of organisational context variables such as managerial style and organisational culture, and other contingencies such as life cycle stage, union intensity, capital intensity, and size. Thus, the contribution of this study is two-fold. First on the analytical level, adopting a more sophisticated method of analysis, and second on the conceptual level, introducing an HRD-performance linkage model.

Analytically, Table 2 shows the direct, indirect and total effects of statistically significant relationships expressed in the tested model. Results shown in Table 2 reveal that resourcing and development, and skills and attitudes are positively influenced by the 'organisational context' variable. This means that the more heavily decentralised the management style is, and the more fulfilment - oriented (i.e. emphasis on expertise and orientation toward the person) organisational culture is, the more positive is the influence of organisational context variables on the resourcing and development and HRD outcomes. Furthermore, although there is no any direct impact of organisational context on behaviour and organisational performance, their indirect impacts on organisational performance are very strong ( 0.99 and 0.90 respectively). In fact, total effects indicate that all variables are strongly and positively influenced by organisational context variables. This result seems to be very important because it reveals that the internal environment of the organisation influences employee resourcing and development, and the HRD outcomes of skills, attitudes and behaviour of the employees, which in turn affect organisational performance. Moreover, it is worth mentioning that the variables of employee retention and presence fit into the model, supporting the findings of other researchers such as Boselie et al. (2001) and Fey et al. (2000), who advocate that they affect organisational performance.

With respect to the latent variable of 'organisational performance' it is seen that all the variables (effectiveness, efficiency, development, satisfaction, innovation, quality) used to constitute this construct fit properly into the model. However, path coefficients reveal that organisational performance is moderately and negatively influenced by the other 'contingencies' variable, supporting thus the argument of Kuchinke (2003) that organisations do not operate in a vacuum. Specifically, with the introduction of the 'life cycle stage' variable we tried to capture maturity effects of the organisation, or to assess the stage of organisational development. It is argued that HRD policies change over time depending on whether the organisation is in a stage of formation, growth, maturity, or decline (Budhwar \& Sparrow, 1997). In this study, we found that the life cycle stage has negative effects on organisational performance. This result may be taken to support the results of Delaney \& Huselid (1996) and Katou \& Budhwar (2007).

There is much evidence that unions affect a firm's performance (Freeman \& Medoff 1984). In our study, we found that union intensity is negatively related to organizational performance. This finding contradicts the results of Huselid (1995) who support that the degree of unionization is positively related to productivity, but agree with the results of Delbridge \& Whitfield (1999) who argue that union presence is negatively related to the employee satisfaction with the amount of influence over a job, and Katou \& Budhwar (2007) who support that union intensity is negatively related to organizational performance. In our research, we found that capital intensity 
and size are negatively related to organizational performance, contradicting thus with the results of Huselid (1995), Richard \& Johnson (2001), and Katou \& Budhwar (2007). However, these results suggest that as organisations increase in size and capital, organisational performance becomes weaker rather than stronger.

Table 2: Standardised total, direct and indirect effects

\begin{tabular}{|c|c|c|c|c|}
\hline Descriptions & & $\begin{array}{l}\text { Direct } \\
\text { effects }\end{array}$ & $\begin{array}{l}\text { Indirect } \\
\text { effects }\end{array}$ & $\begin{array}{l}\text { Total } \\
\text { effects }\end{array}$ \\
\hline $\begin{array}{l}\text { Organisational } \\
\text { context }\end{array}$ & $\rightarrow$ Organisational performance & 0.00 & 0.90 & 0.90 \\
\hline $\begin{array}{l}\text { Organisational } \\
\text { context }\end{array}$ & $\rightarrow$ Behaviour & 0.00 & 0.99 & 0.99 \\
\hline $\begin{array}{l}\text { Organisational } \\
\text { context }\end{array}$ & $\rightarrow$ Attitudes & 0.68 & 0.28 & 0.96 \\
\hline $\begin{array}{l}\text { Organisational } \\
\text { context }\end{array}$ & $\rightarrow$ Skills & 0.45 & 0.34 & 0.79 \\
\hline $\begin{array}{l}\text { Organisational } \\
\text { context }\end{array}$ & $\rightarrow$ Development & 0.16 & 0.60 & 0.76 \\
\hline $\begin{array}{l}\text { Organisational } \\
\text { context }\end{array}$ & $\rightarrow$ Resourcing & 0.81 & 0.00 & 0.81 \\
\hline Contingencies & $\rightarrow$ Organisational performance & -0.10 & 0.00 & -0.10 \\
\hline Behaviour & $\rightarrow$ Organisational performance & 0.66 & 0.00 & 0.66 \\
\hline Attitudes & $\rightarrow$ Organisational performance & 0.00 & 0.67 & 0.67 \\
\hline Attitudes & $\rightarrow$ Behaviour & 1.00 & 0.00 & 1.00 \\
\hline Skills & $\rightarrow$ Organisational performance & 0.00 & 0.24 & 0.24 \\
\hline Skills & $\rightarrow$ Behaviour & 0.00 & 0.37 & 0.37 \\
\hline Skills & $\rightarrow$ Attitudes & 0.36 & 0.00 & 0.36 \\
\hline Development & $\rightarrow$ Organisational performance & 0.33 & 0.10 & 0.43 \\
\hline Development & $\rightarrow$ Behaviour & 0.00 & 0.16 & 0.16 \\
\hline Development & $\rightarrow$ Attitudes & 0.00 & 0.16 & 0.16 \\
\hline Development & $\rightarrow$ Skills & 0.44 & 0.00 & 0.44 \\
\hline Resourcing & $\rightarrow$ Organisational performance & 0.00 & 0.32 & 0.32 \\
\hline Resourcing & $\rightarrow$ Behaviour & 0.00 & 0.12 & 0.12 \\
\hline Resourcing & $\rightarrow$ Attitudes & 0.00 & 0.12 & 0.12 \\
\hline Resourcing & $\rightarrow$ Skills & 0.00 & 0.33 & 0.33 \\
\hline Resourcing & $\rightarrow$ Development & 0.74 & 0.00 & 0.74 \\
\hline
\end{tabular}

It is seen in Table 2 that behaviour (retention, presence) is strongly and positively related to attitudes (commitment, satisfaction, motivation). This direct relation between attitudes and behaviour (1.00) is transferred to organisational performance, depicted by the total effect of behaviour on performance $(0.66)$ that is almost equal to the total effect of attitudes on performance (0.67). This result supports the job performance theory (Campbell, 1990), advocating that it is employee's attitudes that have an impact on the behaviour of employees that subsequently has an impact on organisational performance (Wright et al., 2003). The processes of resourcing and development provided an indirect (0.33) and a direct (0.44) effect on skills, which subsequently it is translated to increased organisational performance $(0.24)$ through attitudes and behaviour (Fey et al., 2000; Wright et al., 2003). Generally, resourcing 
and development influence organisational performance either directly or indirectly ( 0.32 and 0.43 for resourcing and development respectively), agreeing thus with Guest (2001) and Shih et al. (2006). Furthermore, path coefficients indicated that 'resourcing" (recruitment, selection, separation, flexible work) is heavily and directly (0.81) influenced by organisational context, although 'development' (individual and team training and development, monitoring training and development, careers, work design, performance appraisal) is strongly and indirectly (0.60) influenced by organisational context. It is worth mentioning that although Becker \& Gerhart (1996) have identified only three HRM policies that influence organisational performance to be common among various empirical studies, we decided to include in this study as many HRM policies as possible, considering that the proposed research model is tested for the first time in the Greek context using structural equation modelling.

In terms of mediation we found that skills, attitudes, and behaviour serially mediate the relationship between development and organisational performance. This finding coincides with Doty \& Delery (1997) and Fey et al. (2000) who argued that HRM policies influence organisational performance by creating a workforce that is skilled and has the right attitudes and behaviour. It also partially supports Guest (2001) for satisfaction and commitment, Boselie et al. (2001) for satisfaction and motivation, Horwitz (1999) for obtaining competencies in an ever-expanding collection of skills, and Paul \& Anantharaman (2003) for competence and commitment, arguing that these HRM outcomes affect organisational performance. Furthermore, our results support Purcell, Kinnie, Hutchinson, Rayton, \& Swart (2003) who advocate that employee commitment and motivation are important mediators between training and firm performance.

Summarising, we may say that the results of this study support that HRD policies positively affect organisational performance of Greek manufacturing companies. Specifically, the relationship between development and organisational performance, is serially mediated through the HRD outcomes of skills, attitudes and behaviour, and is moderated by resourcing, organisational context and other contingencies, giving thus empirical evidence for the basic causal pathway of Resourcing $\rightarrow$ Development $\rightarrow$ Skills $\rightarrow$ Attitudes $\rightarrow$ Behaviour $\rightarrow$ Performance, stated above. Consequently, this paper not only supports that resourcing and development have a positive impact on organisational performance, also explains the mechanisms through which resourcing and development improve organisational performance and that too in a non US/UK context where most of research related to field has been conducted.

The conclusions above, nonetheless, should be treated with caution. This is mainly because a single respondent from each organisation provided information on resourcing and development, HRD outcomes of skills, attitudes and behaviour, and perceived measures of organisational performance, respondent bias may have set in the form of upward or downward reporting of the measures (Paul \& Anatharaman, 2003; Mabey \& Gooderham, 2005). In spite of such limitations, the study makes some important contributions. It tests theoretical assumptions in smaller firms and in a non- USA/UK context. It provides support to the mediation perspective. The study supports for the use of skills, attitudes, and behaviours as serially mediating variables between resourcing and development, and organisational performance. Thus, the research suggests that models depicting direct relationships between 
resourcing and development and organisational performance may be too simplistic and does not show the causalities involved. This meets the advice of Becker and Gerhart (1996) and Fey et al. (2000) to test models with mediating variables such as HRD outcomes, using the methodology of structural equation modelling, and thus, contributing to this academic area of research.

The argument that HRD makes an impact on the bottom line may still be in dispute (Swanson, 1998; Bartlett, 2001). However, what is of interest is in knowing how this impact has taken place. Thus, a managerial implication of this study is not only the demonstration that resourcing and development are positively related to organisational performance in the Greek context, but also that employee skills, attitudes, and behaviours are three major components of the "black-box" that generate organisational competitiveness from resourcing and development. Managers should recognise that changes in employee skills, attitudes, and behaviours that are caused by resourcing and development precede changes in organisational performance (Katou \& Budhwar, 2006).

Considering the limitations of the study we may propose paths for future research. Specifically, in this study we tried to explore the question of causality using crosssection data. However, causality can only really be tested with data collected at different points in time. Thus, the field would greatly benefit from some time-series or longitudinal studies in the future (Katou \& Budhwar, 2006), where the lagged effects of skills, attitudes and behaviour outcomes of development may further contribute to our understanding of how HRD improve organizational performance (Ellinger et al., 2002). Further, considering the pace of globalisation, there is a strong need for such investigations in emerging markets, through the inclusion of organizational structure, leadership style and corporate strategy (Lopez et al., 2005). What it seems clear for the moment is to find evaluation and decision contingent models that work and will be easily applied in real world particular instances (Lyntham et al., 2004; Holton \& Naquin, 2005).

\section{References}

Alcazar, F. M., Fernandez, P. M. R., \& Gardey, G. S. (2005). Researching on SHRM: An analysis of the debate over the role played by human resources in firm success. Management Revue, 16, 213-241.

Appelbaum, S. H., \& Reichart, W. (1998). How to measure an organization's learning ability: The facilitating factors - Part II. Journal of Workplace Learning, 10(1), 15-28.

Baldwin, T. T., \& Danielson, C. C. (2002). Invited reaction: Linking learning with financial performance. Human Resource Development Quarterly, 13(1), 23-29.

Bartlett, K. R. (2001). The relationship between training and organizational commitment: A study in the health care field. Human Resource Development Quarterly, 12(4), 335-352. 
Bates, R. (1999). Measuring performance improvement. In R.J. Torraco (Ed.), Performance improvement theory and practice. Baton Rouge, LA: Academy of Human Resource Development.

Becker, B. E., \& Gerhart, B. (1996). The impact of human resource management on organisational performance: progress and prospects. Academy of Management Journal, 39, 779-801.

Becker, B. E., \& Huselid, M. A. (1998). High performance work systems and firm performance: A synthesis of research and managerial implications. In G.R. Ferris (Ed.), Research in personnel and human resources. Stamford, CT: JAI Press.

Black, W. C. (2001). Invited reaction: The influence of individual characteristics and the work environment on varying levels of training outcomes. Human Resource Development Quarterly, 12(1), 25-31.

Boselie, P., Paauwe, J., \& Jansen, P. (2001). Human resource management and performance: lessons from the Netherlands. International Journal of Human Resource Management, 12, 1107-1125.

Brewster, C., \& Hegewisch, A. (1994). Hunan resource management in Europe: Issues and opportunities. In C. Brewster, and A. Hegewisch (Eds.), Policy and practice in European human resource management: The Price Waterhouse Cranfield Survey. London: Routledge.

Budhwar, P., \& Sparrow, P. R. (1997). Evaluating levels of strategic integration and devolvement of human resource management in India. The International Journal of Human Resource Management, 8, 476-494.

Campbell, J. (1990). Modeling the performance prediction problem in industrial and organizational psychology. In M. Dunnette, and L. Hough (Eds.), Handbook of Industrial and Organizational Psychology. Palo Alto, CA: Consulting Psychologists Press.

Chalofsky, N.E. (1998). Professionalization comes from theory and research: The 'why' instead the 'how' to. In R. J. Torraco (Ed.), Proceedings of the Academy of Human Resource Development Annual Conference. Baton Rouge, LA: Academy of Human Resource Development.

Chiu, R. K., \& Francesco, A. M. (2003). Dispositional traits and turnover intention: Examining the mediating role of job satisfaction and affective commitment. International Journal of Manpower, 24(3), 284-299.

Delaney, J. T., \& Huselid, M.,A. (1996). The impact of human resource management practices on perceptions of organizational performance. Academy of Management Journal, 39, 949-969.

Delbridge, R., \& Whitfield, K. (2001). Employee perceptions of job influence and organisational participation. Industrial Relations, 40, 472-489. 
Delery, J., \& Doty, D. H. (1996). Modes of theorizing in strategic human resource management: test of universalistic, contingency and configurational performance predictions. Academy of Management Journal, 39, 802-835.

Doty, D. H., \& Delery, J.,E. (1997). The importance of holism, interdependence, and equifinality assumptions in high performance work systems: Toward theories of the high performance work force. Academy of Management Annual Meeting. Boston, MA.

Elangovan, A. R. (2001). Causal ordering of stress, satisfaction and commitment, and intention to quit: A structural equations analysis. Leadership and Organization Development Journal, 22(4), 159-166.

Ellinger, A. D., Ellinger, A. E., Yang, B., \& Howton, S. W. (2002). The relationship between the learning organization concept and firms' financial performance: An empirical assessment. Human Resource Development Quarterly, 13(1), 5-21.

Ferris, G. R., Hochwarter, W. A., Buckley, M. R., Harrel-Cook, G., \& Frink, D. D. (1999). Human resources management: some new directions. Journal of Management, 25(3), 385-415.

Ferris, G. R., Perrewe, P. L. Ranft, A. L., Zinko, R., Stoner, J. S. Brouer, R. L., \& Laird, M. D. (2007). Human resources reputation and effectiveness. Human Resource Management Review, 17, 117-130.

Fey, C. F., Bjorkman, I., \& Pavlovskaya, A. (2000). The effect of human resource management practices on firm performance in Russia. International Journal of Human Resource Management, 11, 1-18.

Freeman, R. B., \& Medoff, J. L. (1984). What Unions do? New York: Basic Books.

Garavan, T. N., Gunnigle, P., \& Morley, M. (2000). Contemporary HRD research: a triarchy of theoretical perspectives and their prescriptions for HRD. Journal of European Industrial Training, 24(2/3/4), 65-93.

Garavan, T. N., McGuire, D., \& O' Donnell, D. (2004). Exploring human resource development: A levels analysis approach. Human Resource Development Review, 3(4), 417-441.

Gerhart, B. (2005). Human resources and business performance: Findings, unanswered questions, and an alternative approach. Management Revue, 16, 174-185.

Gomez-Mejia, L. R., Balkin, D. B., \& Cardy, R. L. (2004). Managing human resources. Upper Saddle River, NJ: Prentice Hall.

Guest, D. (1997). Human resource management and performance: a review and research agenda. International Journal of Human Resource Management, 8, 263-276. 
Guest, D. E. (2001). Human resource management: when research confronts theory. International Journal of Human Resource Management, 12, 1092-1106.

Hair, F., Anderson, R., Tatham, R., \& Black, W. (1995). Multivariate Data Analysis with Readings. ( $4^{\text {th }}$ ed.), London: Prentice-Hall.

Hall, L., \& Torrington, D. (1998). The human resource function: The dynamics of change and development. London: Financial Times/Pitman Publishing.

Hansen, C. D. (1998). HRD theory building through qualitative research. In R. J. Torraco (Ed.), Proceedings of the Academy of Human Resource Development Annual Conference. Baton Rouge, LA: Academy of Human Resource Development.

Hardre, P. L. (2003). Beyond two decades of motivation: A review of the research and practice in instructional design and human performance technology. Human Resource Development Review, 2(1), 54-81.

Harman, H. H. (1967). Modern factor analysis. Chicago, IL: University of Chicago Press.

Hatcher, T. (1999). Reorienting the theoretical foundations of human resource development: Building a sustainable profession and society. In P. K. Kuchinke (Ed.), Proceedings of the Academy of Human Resource Development Annual Conference. Baton Rouge, LA: Academy of Human Resource Development.

Holton, E. F. III (2002). Defining HRD: Too much of a good thing? Human Resource Development Review, 1(3), 275-276.

Holton, E. F. III, \& Naquin, S. (2005). A critical analysis of HRD evaluation models from a decision-making perspective. Human Resource Development Quarterly, 16(2), 257-280.

Horwitz, F. M. (1999). The emergence of strategic training and development: the current state of play. Journal of European Industrial Training, 23(4/5), 180-190.

Huselid, M. A. (1995). The impact of human resource management practices on turnover, productivity and corporate financial performance. Academy of Management Journal, 38, 635-670.

Jöreskog, K. G., \& Sörbom, D. (2004). LISREL 8.7 for Windows [Computer Software]. Lincolnwood, IL: Scientific Software International, Inc.

ICAP (2001). Electronic Data Base. Athens: Greece.

Katou, A. A., \& Budhwar, P. S. (2006). Human resource management systems and organizational performance: a test of a mediating model in the Greek manufacturing context. International Journal of Human Resource Management, 17, 1223-1253. 
Katou, A. A., \& Budhwar, P. S. (2007). The effect of human resource management policies on organisational performance in Greek manufacturing firms.

Thunderbird International Business Review, 49(1), 1-35.

Kirkpatrick, D. (1998). Evaluating training programs: The four levels. (2 ${ }^{\text {nd }}$ ed.), San Francisco: Berrett-Koehler.

Kuchinke, K. P. (2003). Contingent HRD: Toward a theory of validation and differentiation in formal human resource development. Human Resource Development Review, 2(3), 294-309.

Lopez, S. P., Peon, J. M. M., \& Ordas, C. J. V. (2005). Human resource practices, organizational learning and business performance. Human Resource Development International, 8(2), 147-164.

Lynham, S. A. (2000). Theory building in the human resource development profession. Human Resource Development Quarterly, 11(2), 159-178.

Lynham, S. A., Chermack, T. J., \& Noggle, M. A. (2004). Selecting organizational development theory from an HRD perspective. Human Resource Development Review, 3(2), 151-172.

Mabey, C., \& Gooderham, P. N. (2005). The impact of management development on perceptions of organizational performance in European firms. European Management Review, 2, 131-142.

Mabey, C., \& Ramirez, M. (2005). Does management development improve organizational productivity? A six-country analysis of European firms. The International Journal of Human Resource Management, 16(7), 1067-1082.

Mayo, A. (2000). The role of employee development in the growth of intellectual capital. Personnel Review, 29(4), 521-533.

Miles, R. E., \& Snow, C. C. (1984). Organisational Strategy, Structure, and Process. Tokyo: McGraw-Hill Kogahusha.

Noe, R. A. (2002). Employee training and development. ( $2^{\text {nd }}$ ed.), New York: McGraw-Hill Irwin.

Nunnally, J. C. (1978). Psychometric theory. New York: McGraw-Hill.

Paul, A. K., \& Anantharaman, R. N. (2003). Impact of people management practices on organisational performance. International Journal of Human Resource Management, 14, 1246-1266.

Pritchard, R. D. (1992). Organizational productivity. In M.D. Dunnette, and L. M. Hough (Eds.), Handbook of industrial and organizational psychology. (2 ${ }^{\text {nd }} \mathrm{ed}$.), Palo Alto, CA: Consulting Psychologists Press. 
Purcell, J., Kinnie, N., Hutchinson, S., Rayton, B., \& Swart, J. (2003). Understanding the people and performance link: Unlocking the black box. London: Chartered Institute of People Development.

Raghuram, S. (1994). Linking staffing and training practices with business strategy: A theoretical perspective. Human Resource Development International, 5(3), 237-251.

Richard, O. C., \& Johnson, N. B. (2001). Strategic human resource management effectiveness and firm performance. International Journal of Human Resource Management, 12, 299-310.

Schuler, R. S., \& Jackson, S. E. (Eds.) (1999). Strategic Human Resource Management: A Reader. London: Blackwell Publishers.

Schuler, R. S., \& Jackson, S. E. (2005). A quarter-century review of human resource management in the U.S.: The growth in importance of the international perspective. Management Revue, 16, 11-35.

Sekaran, U. (1992). Research methods for business: A skill building approach. $\left(2^{\text {nd }}\right.$ ed.), New York: John Wiley \& Sons.

Shih, H.-A., Chiang, Y.-W., \& Hsu, C.-C. (2006). Can high performance work systems really lead to better performance? International Journal of Manpower, 27(8), 741-763.

Snell, S. A., Lepak, D. P., \& Youndt, M. A. (1999). Managing the architecture of intellectual capital: Implications for strategic human resource management. Research in Personnel and Human Resources Management, 4, 175-193.

Swanson, R. A. (1995). Human resource development: Performance is the key. Human Resource Development Quarterly, 6(2), 207-213.

Swanson, R. A. (1998). The witch doctor's pharmacist. Human Resource Development International, 1(1), 7-8.

Swanson, R. A., \& Holton, E. F.III (Eds.) (1997). Human resource development handbook: Linling research and practice. San Francisco: Berrett-Koehler.

Swanson, R.A., \& Holton, E.F.III (Eds.) (2001). Foundations of human resource development. San Francisco: Berrett-Koehler.

Torraco, R.J. (1997). Theory-building research methods. In R. A. Swanson, \& E. F. III Holton (Eds.), Human resource development handbook: Linking research and practice. San Francisco: Berrett-Koehler.

Torraco, R.J. (1999). Advancing our understanding of performance improvement. In R.J. Torraco (Ed.), Performance improvement theory and practice. Baton Rouge, LA: Academy of Human Resource Development. 
Torraco, R. J. (2004). Challenges and choices for theoretical research in human resource development. Human Resource Development Quarterly, 15(2), 171188.

Tracey, J. B., Hinkin, T. R., Tannenbaum, S., \& Mathieu, J. E. (2001). The influence of individual characteristics and the work environment on varying levels of training outcomes. Human Resource Development Quarterly, 12(1), 5-23.

Trompenaars, F. (1993). Riding the Waves of Culture. Chicago, IL: Irwin.

Turnbull, S. (2002). Briclolage as an alternative approach to human resource development theory building. Human Resource Development Review, 1(1), 111-128.

Ulrich, D. (1997). Measuring human resource: an overview of practice and a prescription for results. Human Resource Management, 36, 303-320.

Vandenberg, R. J., \& Lance, C. E. (1992). Examining the causal order of job satisfaction and organizational commitment. Journal of Management, 18(1): 153-167.

Wang, G. (2002). Control group methods for HPT program evaluation and measurement. Performance Improvement Quarterly, 15(2), 32-44.

Wang, G. G., Dou, Z., \& Li, N. (2002). A systems approach to measuring return on investment for HRD interventions. Human Resource Development Quarterly, 13(2), 203-224.

Weinberger, L. A. (1998). Commonly held theories of human resource development. Human Resource Development International, 1(1), 75-93.

Williams, A. P. O. (2001). A brief-focused process of organizational learning. Journal of Management Studies, 38(1), 65-87.

Wimbiscus, J. J. Jr. (1995). A classification and description of human resource development scholars. Human Resource Development Quarterly, 6(1), 5-34.

Wood, S. (1999). Human resource management and performance. International Journal of Management Reviews, 1, 367-413.

Wright, P. M., Gardner, T. M., \& Moynihan, L. M. (2003). The impact of HR practices on the performance of business units. Human Resource Management Journal, 13, 21-36. 